\title{
Influence of duodenal infusions of EPA and DHA on the lipidic milk secretion of the dairy goat
}

\author{
C Léger, D Sauvant, J Hervieu, F Ternois
}

INRA, Station de Nutrition et Alimentation de I'INA-PG, 16, rue Claude-Bernard, 75231 Paris cedex 05, France

The eicosapentaenoic (20:5 $\in, n-3$, EPA) and decosahexaenoic $(22: 6 \epsilon, n-3, D H A)$ acids are known to inhibit the acyl transfer to 1,2-diacylglycerol, the final step of the triglyceride synthesis. An experiment was undertaken to study the effect of these acids on goat nutrition and milk lipidic secretion.

Seven lactating goats equipped with duodenal cannulae have followed 3 periods ( $P 1, P 2, P 3)$ the durations of which were 2,5 and 2 weeks respectively. During the experimental period, $\mathrm{P2}$, the goats were duodenally perfused, twice a day after milking with an emulsion providing $4 \mathrm{~g} / \mathrm{d}$ of EPA + DHA. Statistical analyses were performed by comparing the experimental data to the previous (1) and following (2) subperiods.

The raw milk yield was not influenced and decreased by 24 and $42 \mathrm{~g} / \mathrm{d}$ between $\mathrm{P} 1$ and $\mathrm{P} 2$, and $\mathrm{P} 2$ and $\mathrm{P} 3$, respectively. The milk fat yield decreased by $13.34 \mathrm{~g} / \mathrm{d}(-17 \%, p<0.07)$ between $P 1$ and $P 2$ and increased by $10.15 \mathrm{~g} / \mathrm{d}$ between $P 2$ and $P 3$. The milk fat content decreased by $5.9 \mathrm{~g} / \mathrm{kg}(-17.3 \%, P<0.02)$ between $\mathrm{P} 1$ and $\mathrm{P} 2$ and increased of $3.9 \mathrm{~g} / \mathrm{kg}(P<0.12)$ between $P 2$ and P3. By considering the time partition of milk fat secretion within a day it appeared that the infusion effect was essentially significant on the fat secretion of the morning milking: $-9.83(P<$ $0.001)$ and $+10.83(P<0.05) \mathrm{g} / \mathrm{d}$ between $P 1$ and $P 2$, and $P 2$ and $P 3$, respectively. There were also alterations in the milk fatty acid composition. There was a noticeable decrease of the percentage of $18: 0+18: 1$ between $P 1$ and $P 2$ of $-3.03 \%(P<0.025)$ and an increase of $1.77 \%$ (ns) between P2 and P3. These modifications were cumulated with the variations of the milk fat content and secretion when the sum 18:0 + 18:1 was expressed in $\mathrm{g} / \mathrm{kg}$ and $\mathrm{g} / \mathrm{d}$.

The differences P1-P2 and P3-P2 were -0.64 (ns) and $-1.37(P<0.02) \mathrm{g} / \mathrm{kg}$ for lactose content, $+0.5(P<0.015)$ and -0.09 (ns) $\mathrm{g} / \mathrm{kg}$ for ash content, $-52(P<0.015)$ and $+1(\mathrm{~ns}) \mathrm{mg} / \mathrm{l}$ for plasma glucose content, -23 (ns) and -2 (ns$\mu e q / 1$ for plasma non-esterified fatty acids, and +35 (ns) and -37 (ns) $\mathrm{mg} / \mathrm{l}$ for plasma urea.

In conclusion, the infusions of EPA and DHA induced a reversible decrease of milk fat secretion and modifications of the milk fatty acid profile. These results are important in the context of milk fat quotas. 